\title{
The virtual teams: E-leaders challenges
}

\begin{abstract}
In most of the organizations, the collaboration across time, culture, and geographical boundaries has become one of the common practice and has given rise to the concept of globally teams known as virtual teams. Virtual teams use technologies to communicate with each other such as email, video conference, and text messages. Based on a review of the literature on virtual teams' management, this paper identifies the main challenges of the management such as communication technologies, cultural diversity, E-ethics, and trust. This paper aims to highlight these challenges, assess and analyze published contemporary literature addressing these challenges to improve the virtual teams' management by E-leaders.

Keyword: Communication technologies; E-leaders; E-leadership; Management; Virtual teams
\end{abstract}

